\title{
SELEÇÃO DE ISOLADOS DO FUNGO ENTOMOPATOGÊNICO METARHIZIUM ANISOPLIAE (METSCH.) SOROK. VISANDO O CONTROLE DA BROCA DA CANA-DE-AÇÚCAR DIATRAEA SACCHARALIS (FABR., 1794)
}

\section{L.O.Zappelini* , J.E.M. Almeida, A. Batista Filho, F.H.C. Giometti*}

Instituto Biológico, Centro Experimental Central, CP 70, CEP 13001-970, Campinas, SP, Brasil. E-mail: luczappelini@hotmail.com

\section{RESUMO}

Este trabalho teve por objetivo testar alguns isolados do fungo entomopatogênicos Metarhizium anisopliae em condições de laboratório. Inicialmente, foi calculado o valor da concentração letal $\left(\mathrm{CL}_{90}\right)$, que ficou estabelecido em $5 \times 10^{8}$ conídios/mL. Na continuidade, foram utilizados 27 isolados diferentes, sendo estes testados quanto a sua patogenicidade e virulência em lagartas de Diatraea saccharalis (Lepidoptera: Crambidae) com aproximadamente 1,5 cm, onde os melhores isolados (mortalidades confirmadas acima de 80\%) foram novamente testados, a fim de se obter uma confirmação dos resultados. Em seguida, foram calculados os valores do tempo letal $\left(\mathrm{TL}_{50}\right)$ para os melhores isolados, sendo estes submetidos à produção massal em arroz pré-cozido, verificando-se a esporulação média desses isolados. De uma maneira geral, as mortalidades confirmadas entre os 27 isolados variaram entre 54 a 100\%, sendo que os IBCB 167, 351, 383, 384, $410,417,418,425$ e 481 foram capazes de provocar mortalidades superiores a $80 \%$. Quanto ao tempo letal $\left(\mathrm{TL}_{50}\right)$, o IBCB 383 apresentou o menor tempo com 6,83 dias e a maior conidiogênese foi registrada para o IBCB 417 com 2,52 x 10 conídios/g.

PALAVRAS-CHAVE: Controle microbiano, produção de entomopatógenos, pragas da cana-deaçúcar.

\section{ABSTRACT}

SELECTION OF ISOLATES OF THE ENTOMOPATHOGENIC FUNGUS METARHIZIUM ANISOPLIAE (METSCH.) SOROK., AIMING AT THE CONTROL OF THE SUGARCANE BORER DIATRAEA SACCHARALIS (FABR., 1794). Aiming to improve the methods for controlling the sugarcane borer, Diatraea saccharalis, this study tested some strains of the entomopathogenic fungus Metarhizium anisopliae under laboratory conditions. Initially, the value of the lethal concentration $\left(\mathrm{LC}_{90}\right)$ was calculated, and set at $5 \times 10^{8}$ conidia/mL. Next, 27 different strains were tested for their pathogenicity and virulence in regard to larvae of $D$. saccharalis of approximately $1.5 \mathrm{~cm}$, with retesting of the best isolates (confirmed mortalities above $80 \%$ ) to confirm the results. Next, the values of lethal time $\left(\mathrm{LT}_{50}\right)$ were calculated for the best strains, which were mass produced on pre-cooked rice, verifying the average sporulation of these isolates. Generally, the mortality confirmed among the 27 isolates ranged from 54 to 100\%, with IBCB 167, 351, 383, 384, 410, 417, 418,425 and 481 able to generate mortality over $80 \%$. In terms of lethal time $\left(\mathrm{LT}_{50}\right)$, IBCB 383 showed a shorter time of 6.83 days, while the greatest conidiogenesis was recorded for IBCB 417, with $2.52 \times 10^{9}$ conidia/g.

KEY WORDS: Microbial control, entomopathogenic production, sugarcane pests.

\section{INTRODUÇÃO}

A cana-de-açúcar (Saccharum spp.), uma poaceae semiperene de origem asiática, é uma das principais culturas no Brasil. A estimativa da produção nacional de cana-de-açúcar na safra 2007/2008, é de 528 mi- lhões de toneladas, superior à safra passada em $11,2 \%$ (IEA, 2008). A área ocupada com essa cultura no Brasil é de 6,6 milhões de hectares, superior em 7,4\% (456,9 mil hectares) à safra anterior. Esse comportamento do mercado está relacionado diretamente com o avanço das exportações do açúcar e à maior deman-

\footnotetext{
*Mestrando em Sanidade Vegetal, Alimentar e Ambiental no Agronegócio do Instituto Biológico.
} 
da interna de álcool com o aumento de venda dos carros com motorização baseada na nova tecnologia flex fuel, carros bicombustíveis (ÚNICA, 2008).

OEstadodeSão Pauloéo maior produtor decanade-açúcar, sendo responsável por aproximadamente $60 \%$ de toda a produção nacional, colhendo e esmagando em torno de 316,7 milhões de toneladas na safra 2007/2008 (UDOP, 2008). Grandes extensões cultivadas com uma mesma cultura favorecem o surgimento de insetos pragas e doenças.

Dentre as várias pragas que ocorrem na cultura da cana-de-açúcar, a broca da cana-de-açúcar, Diatraea saccharalis (Lepidoptera: Crambidae), éuma das principais, especificamente pelos danos ocasionados, caracterizando-se pelo complexo broca-podridão causado por micro-organismos que penetram nos colmos juntamente com a praga, além do dano direto devido à abertura de galerias ao longo da planta (GALlo et al., 2002).

Vários relatos já foram descritos referenciando inimigos naturais como fungos, vírus, bactérias entomopatogênicas, predadores e parasitoides atacando a broca da cana-de-açúcar. Porém, com a introdução de um parasitoide trazido de Trinidad na América Central ${ }^{-}$obraconídeo Cotesiaflavipes ${ }^{-}$é que o sucesso do controle biológico da $D$. saccharalis foi consolidado a partir da década de 70 no Brasil, devido à facilidade de criação massal e a capacidade desta vespinha em localizar seu hospedeiro (GALLO et al., 2002; PINTO, 2006).

Porém, com a rápida expansão da cultura da canade-açúcar, a produção dos parasitoides C. flavipes teria que proporcionalmente acompanhar esse aumento, o quenão seria possível devidoao curto espaço de tempo. Assim, a utilização de outros métodos de controle, como os fungos entomopatogênicos, incrementará o controle biológico da broca da canade-açúcar, além de contribuir na manutenção da baixa utilização de agrotóxicos para o controle de $D$. saccharalis.

Este trabalho teve por objetivo selecionar isolados virulentos e produtivos do fungo $M$. anisopliae em condições de laboratório, visando o controle de $D$. saccharalis.

\section{MATERIALEMÉTODOS}

\section{Isolados de fungos entompatogênicos}

No experimento foram utilizados 27 isolados do fungo entomopatogênico Metarhiziumanisopliae, provenientes da Coleção de Micro-organismos Entomopatogênicos "Oldemar Cardim Abreu" do Laboratório de Controle Biológico do Instituto Biológico, os quais seencontram armazenados em "freezer" a $-12^{\circ} \mathrm{C}$, na forma de conídios puros em tubos plásticos de 1,5 mL (Tabela 1)

Para a realização dos experimentos, os isolados de M. anisopliae foram repicados em placas de Petri, de 9,0 cm de diâmetro, contendo meio de cultura B.D.A. (Batata-Dextrose-Ágar). As placas foram mantidas em câmaras de germinação (B.O.D.) a $25 \pm 1^{\circ} \mathrm{C}$, umidade relativa $70 \pm 10 \%$ e fotoperíodo de 12 horas. $\mathrm{O}$ período de incubação foi de 10 dias, em média, e, após esse período, as placas foram armazenadas em geladeira $\left(4^{\circ} \mathrm{C}\right)$ até a utilização nos experimentos.

Determinação da concentração letal $\left(\mathrm{CL}_{90}\right)$

Foi utilizado como padrão o isolado IBCB 425 ( $M$. anisopliae proveniente de solo de Iporanga, SP), utilizado em diversos programas de controle microbiano de pragas pelo Instituto Biológico.

As suspensões foram preparadas a partir da conidiogênese dos isolados em placas com o meio de cultura sólido B.D.A, descrito no item 3.1, com água destilada, estéril e espalhante adesivo (Tween 80) a 0,1\%. Com o auxílio de um microscópio óptico e uma câmara de Neubauer, foi feita a contagem do número de conídios.

Oexperimento foi composto por cinco tratamentos contendo diferentes concentrações, $5 \times 10^{6} ; 1 \times 10^{7} ; 5$ x $10^{7} ; 1$ x $10^{8}$ e $5 \times 10^{8}$ conídios $/ \mathrm{mL}$ dos isolados considerados padrão, pulverizados em lagartas de $D$. saccharalis no $4^{\circ}$ ínstar $(1,5 \mathrm{~cm}$ de comprimento) com quatro repetições.

As lagartas da broca da cana-de-açúcar foram fornecidas pela Usina São João, sediada no Município de Araras, SP, e eram provenientes de uma criação de laboratório. A aplicação de $1 \mathrm{~mL}$ das suspensões do fungo $M$. anisopliae sobre as lagartas foi realizada com o auxílio de uma Torre de Potter adaptada, com pressão de 15 libras/pol. ${ }^{2}$. Após a pulverização, as lagartas foram transferidas para pequenos potes plásticos $(5 \mathrm{~cm}$ de altura e $4 \mathrm{~cm}$ de diâmetro) com tampas de rosca e tela, contendo um pedaço de colmo de cana-de-açúcar, os quais foram acondicionados em uma sala climatizada com temperatura de $25 \pm 1^{\circ} \mathrm{C}$, umidade relativa $70 \pm 10 \%$ e fotoperíodo de 12 horas.

As avaliações foram realizadas diariamente por um período de 15 dias, onde cada inseto morto era transferido para uma placa de Petri contendo um chumaço de algodão umedecido comágua destilada, estabelecendo-se uma câmara úmida, a fim de proporcionar a extrusão dos fungos pelo tegumento do inseto. As placas foram mantidas em câmara climatizada B.O.D.com temperatura média de $25 \pm 1^{\circ} \mathrm{C}$, fotofasede 12 horas e umidade relativa de $70 \pm 10 \%$. Este procedimento é realizado para confirmação da mortalidade causada pelo entomopatógeno. 
Tabela 1 - Identificação e procedência dos isolados do fungo Metarhizium anisopliae, utilizados nos experimentos com Diatraea saccharalis.

\begin{tabular}{|c|c|c|c|}
\hline Isolado & Hospedeiro & Coletor & Localidade \\
\hline IBCB 116 & Solo & J.E.M. Almeida & Contagem, MG \\
\hline IBCB 153 & Solo & R. Cassol & Aral Moreira, MS \\
\hline IBCB 154 & Solo & R. Cassol & Guaraniaçu, PR \\
\hline IBCB 155 & Solo de gramado & R. Cassol & Cascavel, PR \\
\hline IBCB 156 & Solo & R. Cassol & Cascavel, PR \\
\hline IBCB 158 & Solo & R. Cassol & Cascavel, PR \\
\hline IBCB 159 & Solo & R. Cassol & Cascavel, PR \\
\hline IBCB 167 & Solo & R. Cassol & Cascavel, PR \\
\hline IBCB 171 & Solo de soja & R. Cassol & Aral Moreira, MS \\
\hline IBCB 351 & Solo de cana-de-açúcar & J.E.M. Almeida & Guariba, SP \\
\hline IBCB 352 & Solo de cana-de-açúcar & J.E.M. Almeida & Valparaíso, SP \\
\hline IBCB 353 & Solo de cana-de-açúcar & J.E.M. Almeida & Valparaíso, SP \\
\hline IBCB 360 & Solo de banana & L.G. Leite & Piedade, SP \\
\hline IBCB 361 & Solo de banana & L.G. Leite & Piedade, SP \\
\hline IBCB 363 & Mahanarva fimbriolata & J.E.M. Almeida & Araras, SP \\
\hline IBCB 380 & Mahanarva fimbriolata & L.G. Leite & Água Branca, SP \\
\hline IBCB 382 & Pão-de-galinha pastagem & J.E.M. Almeida & Passo Fundo, RS \\
\hline IBCB 383 & Mahanarvafimbriolata & L.G. Leite & Água Branca, SP \\
\hline IBCB 384 & Mahanarva fimbriolata & L.G. Leite & Sertãozinho, SP \\
\hline IBCB 391 & Mahanarva fimbriolata & J.E.M. Almeida & Tabapuã, SP \\
\hline IBCB 410 & Solo de mata atlântica & E. Denardo & Iporanga, SP \\
\hline IBCB 417 & Solo de mata atlântica & E. Denardo & Iporanga, SP \\
\hline IBCB 418 & Solo de mata atlântica & E. Denardo & Iporanga, SP \\
\hline IBCB 425 & Solo de mata atlântica & E. Denardo & Iporanga, SP \\
\hline IBCB 426 & Solo de mata atlântica & E. Denardo & Iporanga, SP \\
\hline IBCB 478 & Solo de algodão & J.E.M. Almeida & Mogi das Cruzes, SP \\
\hline IBCB 481 & Solo de sorgo & L.G. Leite & Campinas, SP \\
\hline
\end{tabular}

A partir dos dados obtidos pela mortalidade confirmada dos insetos, por meio da análise de Probit, foi possível calcular e determinar a $\mathrm{CL}_{90}$ (concentração letal em conídios / $\mathrm{mL}$ a 90\% dos insetos).

\section{Seleção de isolados de Metarhizium anisopliae (Etapa 1)}

Combasenas concentrações selecionadas noexperimento para determinação da $\mathrm{CL}_{90}$, foram realizados ensaios de seleção, divididos em duas fases devido ao número de isolados (27 de M. anisopliae), sendo sua gr com fungo, o qual foi adicionadoem um tubo deensaio contendo $10 \mathrm{~mL}$ de água destilada mais espalhante adesivo (Tween 80 ) a 0,01\% para a preparação de uma suspensão de conídios. As suspensões foram diluídas equantificadas em câmara deNeubauer, com oauxílio do microscópio óptico com aumento de 400x.

Os valores de produção dos conídios foram submetidos à análise de variância e as médias comparadas por meio do teste de Duncan a 5\% de probabilidade e as médias originais transformadas para análise por Raiz quadrada $x+0,5$.

\section{RESULTADOSEDISCUSSÃO}

\section{Determinação da concentração letal $\left(\mathrm{CL}_{90}\right)$}

Para ofungo M. anisopliae, foi possível observar, ao término das avaliações, que as maiores concentrações foram capazes de gerar as maiores mortalidades confirmadas, ou seja, para $1 \times 10^{8}$ e $5 \times 10^{8}$ conídios $/ \mathrm{mL}$ foram obtidos 26 e $62 \%$ da mortalidade confirmada respectivamente(Tabela 2). Sendo que aos 10 dias das avaliações, a concentração letal $90\left(\mathrm{CL}_{90}\right)$ foi estimada em $5 \times 10^{8}$ conídios /mL (Fig. 1).

Estudando outras pragas que acometem a cultura da cana-de-açúcar, LouREIRoet al. (2005a) observaram que a $\mathrm{CL}_{50}$ para ninfas da cigarrinha da raiz da canade-açúcar (Mahanarva fimbriolata) pulverizadas com M. anisopliae, foi estimada em 1,2 $\times 10^{7}$ conídios $/ \mathrm{mL}$.

REIs et al. (2001), avaliando a virulência de 3 isolados de $M$. anisopliae sobre adultos do carrapato Amblyomma cajennense, verificaram que as maiores mortalidades foram ocasionadas com valores de CL ${ }_{90}$ variando em $6,69 \times 10^{9} .3,77 \times 10^{10}$ e $6,7 \times 10^{10}$ conídios/mL. 


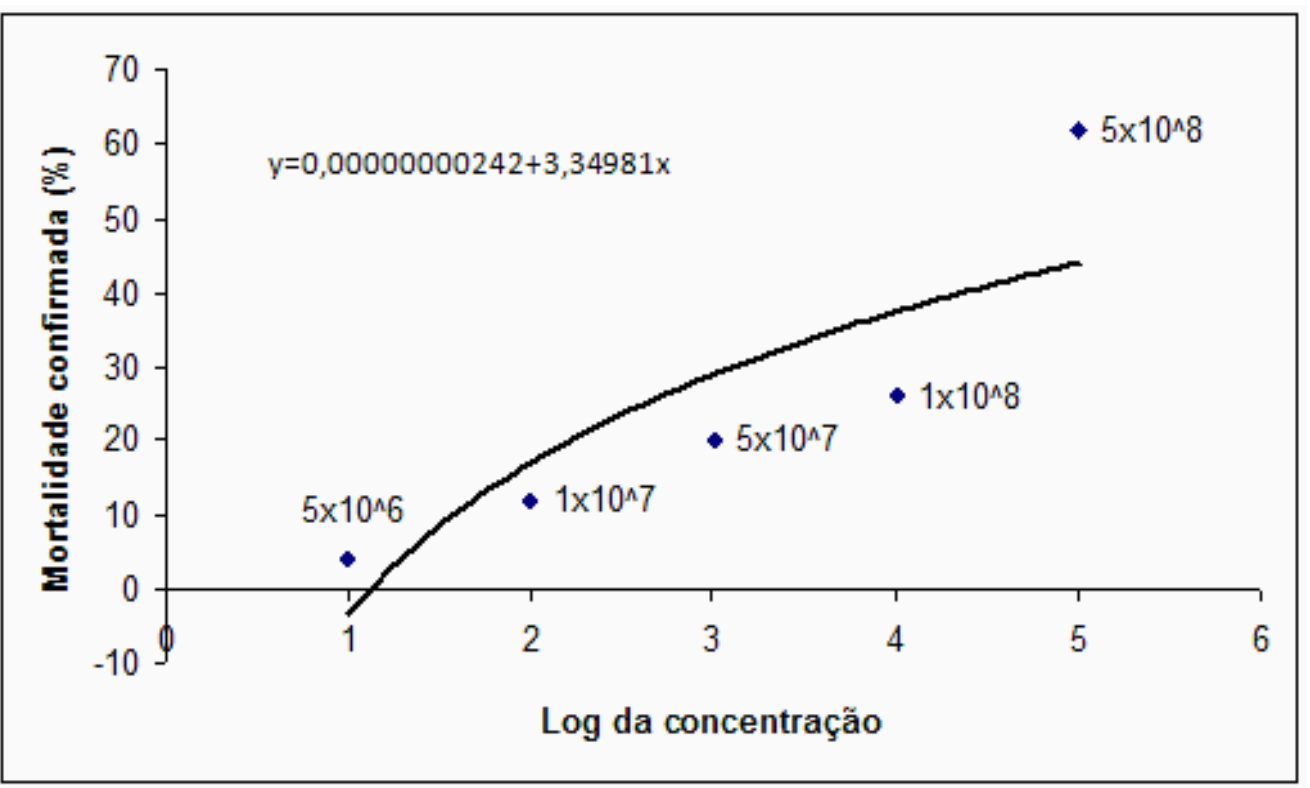

Fig. 1 - Mortalidade de lagartas de D. saccharalis 10 dias após a aplicação do isolado IBCB 66 de Metarhizium anisopliae, nas concentrações de $5 \times 10^{6}, 1 \times 10^{7}, 5 \times 10^{7}, 1 \times 10^{8}$ e $5 \times 10^{8}$ conídios $/ \mathrm{mL}$ (Temp. $25^{\circ} \mathrm{C}$, UR de $70 \%$ e fotofase de 12 horas).

Tabela 2 - Mortalidade confirmada (\%) de D. saccharalis pelo fungo entomopatogênico M. anisopliae (Temp. $25^{\circ} \mathrm{C}$, UR de $70 \%$ e fotofase de 12 horas).

\begin{tabular}{lc}
\hline Tratamentos & $\begin{array}{c}\text { Patógeno } \\
\text { M. anisopliae (IBCB 425) }\end{array}$ \\
\hline $5 \times 10^{6}$ & 4 \\
$1 \times 10^{7}$ & 12 \\
$5 \times 10^{7}$ & 20 \\
$1 \times 10^{8}$ & 26 \\
$5 \times 10^{8}$ & 62 \\
\hline Testemunha & 0 \\
\hline
\end{tabular}

Seleção de isolados de Metarhizium anisopliae (Etapa 1)

Os resultados gerados pelas mortalidades confirmadas dos 27 isolados do fungo $M$. anisopliae evidenciam que todos são patogênicos à broca da cana-deaçúcar, pois a menor mortalidade foi de $49 \%$ do IBCB 158 (Tabela 3). Analisando a mesma tabela podemos observar que somente três isolados foram capazes de causar mortalidades confirmadas iguais ou superiores a $80 \%$, quais sejam: IBCB 425 (82\%), IBCB 351 (90\%) e o IBCB 353 (94\%). Todos os demais não se adequaram ao padrão de seleção pré-estabelecido, pois apresentaram mortalidades confirmadas abaixo de $79 \%$.

Osegundo experimento (Tabela 4) ficou caracterizado pelo fato de que dos 12 isolados testados, sete apresentaram mortalidades confirmadas acima de
$80 \%$, com destaque para o IBCB 417 que controlou $100 \%$ das lagartas de D. saccharalis, seguido pelo IBCB 418 com $96 \%$ de mortalidade confirmada.

Tabela 3 - Mortalidade acumulada (total e confirmada) após 15 dias da aplicação de isolados de Metarhizium anisopliae em lagartas de Diatraea saccharalis (Temp. $25 \pm 1^{\circ} \mathrm{C}$ e Umidade Relativa $70 \pm 10 \%$ e fotofase de 12 horas).

\begin{tabular}{lccc}
\hline Isolado & $\begin{array}{c}\text { N }^{\text {total }} \\
\text { insetos }\end{array}$ & $\begin{array}{c}\text { Mortalidade } \\
\text { total (\%) }\end{array}$ & $\begin{array}{c}\text { Mortalidade } \\
\text { confirmada } \\
(\%)\end{array}$ \\
\hline IBCB 116 & 50 & 86 & 61 \\
IBCB 153 & 50 & 63 & 59 \\
IBCB 154 & 50 & 71 & 66 \\
IBCB 155 & 50 & 55 & 54 \\
IBCB 156 & 50 & 82 & 70 \\
IBCB 158 & 50 & 66 & 49 \\
IBCB 159 & 50 & 98 & 63 \\
IBCB 167 & 50 & 59 & 55 \\
IBCB 171 & 50 & 82 & 77 \\
IBCB 351 & 50 & 81 & 90 \\
IBCB 352 & 50 & 99 & 54 \\
IBCB 353 & 50 & 99 & 94 \\
IBCB 360 & 50 & 88 & 68 \\
IBCB 361 & 50 & 77 & 68 \\
IBCB 363 & 50 & 73 & 72 \\
IBCB 425 & 50 & 85 & 82 \\
Testemunha & 50 & 2 & 0 \\
\hline
\end{tabular}

ACEVEDo et al. (2007), estudando as interações entre diversos entomopatógenos ea broca da cana-de- 
açúcar D. saccharalis, relataram variações nos índices de mortalidade apontam um isolado comoaltamente promissor, pois esse foi capaz de provocar a mortalidade de $100 \%$ das lagartas em seu tratamento, corroborando os dados obtidos com o isolado IBCB 417.

FAVA et al. (2004) novamente apontam diferenças nos valores de mortalidades confirmadas de $D$. saccharalis pelo fungo M. anisopliae, quando aplicado em lagartas de $1^{\circ}$ e $2^{\circ}$ instar em concentrações de 1 a $3 \times 10^{8}$ conídios / $\mathrm{mL}$ em condições de laboratório.

Tabela 4 - Mortalidade acumulada (total e confirmada) após 15 dias da aplicação dos isolados de Metarhizium anisopliae em lagartas de Diatraea saccharalis (Temp. $25 \pm 1^{\circ} \mathrm{C}$ e Umidade Relativa $70 \pm 10 \%$ e fotofase de 12 horas).

\begin{tabular}{lccc}
\hline Isolado & $\begin{array}{c}N^{\text {o }} \text { total } \\
\text { insetos }\end{array}$ & $\begin{array}{c}\text { Mortalidade } \\
\text { total (\%) }\end{array}$ & $\begin{array}{c}\text { Mortalidade } \\
\text { confirmada } \\
(\%)\end{array}$ \\
\hline IBCB 380 & 50 & 075 & 70 \\
IBCB 382 & 50 & 81 & 78 \\
IBCB 383 & 50 & 93 & 85 \\
IBCB 384 & 50 & 97 & 96 \\
IBCB 391 & 50 & 78 & 60 \\
IBCB 410 & 50 & 92 & 84 \\
IBCB 417 & 50 & 100 & 100 \\
IBCB 418 & 50 & 97 & 96 \\
IBCB 425 & 50 & 87 & 86 \\
IBCB 426 & 50 & 78 & 72 \\
IBCB 478 & 50 & 86 & 74 \\
IBCB 481 & 50 & 85 & 80 \\
Testemunha & 50 & 2 & 0 \\
\hline
\end{tabular}

Estas mesmas variações também puderam ser observadas em outros grupos de insetos. CINTRA et al. (2003) observaram mortalidades confirmadas entre 10 e $70 \%$ para ninfas da cigarra-de-café Fidicina sp. XAVIER; Ávila (2005), em teste de patogenicidade de alguns isolados ao percevejo castanho, também observaram variações nos valores das mortalidades confirmadas estando entre 10 e 78\%. LOUREIRO et al. (2005b), selecionando isolados de M. anisopliae à cigarrinha-da-raiz da cana-de-açúcar Mahanarva fimbriolata, relatam que variações entre 10 a $90 \%$ também ocorreram em seus experimentos.

Foi observado que, dentre os 27 isolados de $M$. anisopliae testados, novamente 9 isolados apresentaram mortalidades confirmadas iguais ou superiores a 80\%. Este valor foi ad otado como padrão de seleção dos isolados com bom potencial para o controle da broca da cana-de-açúcar D. saccharalis. As mortalidades ocorreram principalmente entre o $5^{\circ}$ e $12^{\circ}$ dias após a aplicação da suspensão de conídios.

Quando as mortalidades confirmadas dos isolados são dispostas em uma distribuição de frequência (Fig. 2), podemos observar a sua separação em grupos de acordo com as porcentagens, onde 6 isolados controlam entre 41 a $60 \%$ das lagartas, 13 mostraram mortalidades entre 61 e $80 \%$ e outros 8 isolados de $M$. anisopliae alcançaram mortalidades entre 81 e 100\%, sendo estes últimos selecionados para o controle de lagartas de D. saccharalis.

Esses dados corroboram com aqueles obtidos por LOUREIRO et al. (2005b), verificando que a grande maioria do isolados está abaixo do padrão estabelecido anteriormente e apenas uma minoria esta acima do padrão.

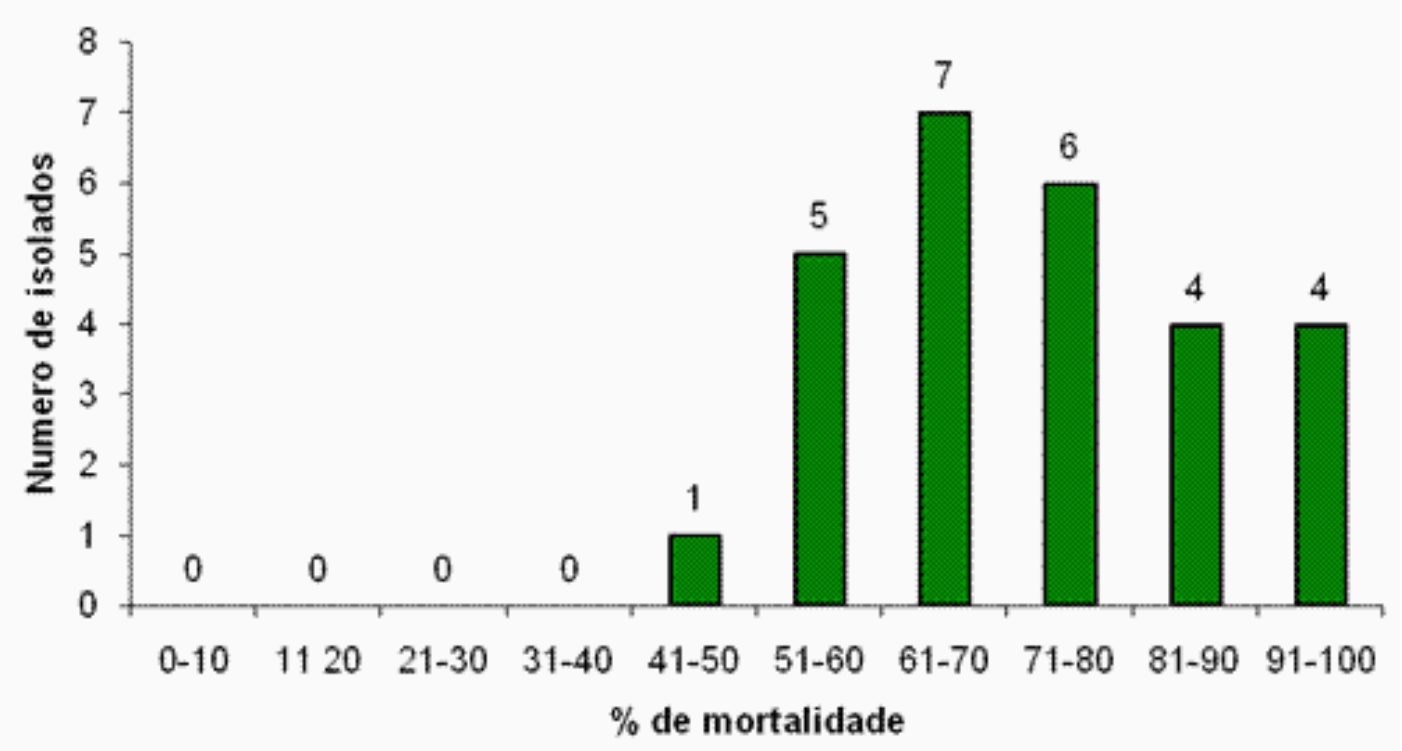

Fig. 2 - Distribuição de frequência de isolados de M. anisopliae em relação ao percentual de mortalidade confirmada causada em lagartas de D. saccharalis. 
Os isolados de $M$. anisopliae selecionados foram: IBCB, 351, 353, 383, 384, 410, 417, 418, 425 e 481.

\section{Seleção final dos isolados de Metarhizium anisopliae (Etapa 2)}

Os isolados de M. anisopliae novamente apresentaram mortalidades iguais ou superiores a $62 \%$, resultados semelhantes e/ou iguais ao primeiro teste de seleção realizado.

Os dados obtidos (Tabela 5) sugerem que houve diferença estatística apenas entre os isolados IBCB 384 e 425. Novamente podemos estabelecer uma relação positiva entre mortalidade confirmada e os valores para $\mathrm{TL}_{50}$, pois foi possível observar que os menores tempos letais ocorreram para os isolados IBCB 384 e 383 com 6,47 e 6,83 dias, respectivamente, os quais provocaram as maiores porcentagens de mortalidades confirmadas, com 90 e $86 \%$, respectivamente, sendo considerados como os mais promissores e virulentos.

Tabela 5 - Mortalidade média de lagartas de Diatraea saccharalis causada por isolados de Metarhizium anisopliae (Temperatura $25 \pm 2{ }^{\circ} \mathrm{C}$ e Umidade Relativa $60 \pm 10 \%$ ).

\begin{tabular}{lcr}
\hline $\begin{array}{l}\text { Isolados } \\
\begin{array}{l}\text { selecionados } \\
\text { de B. bassiana }{ }^{1}\end{array}\end{array}$ & $\begin{array}{c}\text { Mortalidade média } \\
\text { de lagartas }(\mathrm{n}=5)\end{array}$ & $\mathrm{TL}_{50}($ Dias $)$ \\
\hline IBCB 351 & $7,40 \pm 0,89 \mathrm{ab}$ & 9,10 \\
IBCB 353 & $7,40 \pm 2,07 \mathrm{ab}$ & 9,22 \\
IBCB 383 & $8,60 \pm 0,54 \mathrm{ab}$ & 6,83 \\
IBCB 384 & $9,00 \pm 0,00 \mathrm{a}$ & 6,47 \\
IBCB 410 & $7,00 \pm 0,70 \mathrm{ab}$ & 10,25 \\
IBCB 417 & $7,60 \pm 1,81 \mathrm{ab}$ & 8,66 \\
IBCB 418 & $8,20 \pm 0,83 \mathrm{ab}$ & 8,47 \\
IBCB 425 & $6,20 \pm 1,30 \mathrm{~b}$ & 10,21 \\
IBCB 481 & $7,80 \pm 0,83 \mathrm{ab}$ & 8,06 \\
\hline
\end{tabular}

${ }^{1}$ Médias seguidas de mesma letra não diferem entre si pelo teste de Tukey a 5\%. Dados não transformados. CV $=17,0 \%$.

FigUEIREDOet al.(2002), estudandoa patogenicidade de diferentes isolados de $M$. anisopliae sobre a broca gigante da cana de açúcar, puderam observar que os tempos letais a $50 \%$ da população de insetos variaram entre 7,3 a 17,9 dias e estes estavam inversamente relacionados com as crescentes mortalidades confirmadas obtidas, ou seja, existiu também uma correlação positiva entre menor tempo letal com a maior mortalidade.

Essas relações de acréscimo da mortalidade confirmada em função do decréscimo do tempo letal também puderam ser observadas porSILVAetal.(2003) com M. anisopliae sobre lagartas de Plutela xylostella, por CÉSAR FILHO et al. (2001), com lagartas de Alabama argillacea pulverizadas com $M$. anisopliae.

\section{Produção dos melhores isolados em arroz pré- cozido}

Dentre os isolados que foram produzidos em arroz, o IBCB 417 e 481 com uma quantidade média de conídios por grama, respectivamente de 2,52 e 2,46 x $10^{9}$, foram os mais produtivos nesta fase do teste, pois diferiram estatisticamente apenas ao isolado IBCB 353 , sendo que estes não diferiram significativamente dos demais isolados (Tabela 6).

Tabela 6 - Produção média de conídios dos isolados de Metarhizium anisopliae por grama de arroz pré-cozido. (Temperatura $25^{\circ} \mathrm{C}$, Umidade Relativa 60\%).

\begin{tabular}{lc}
\hline Isolados & $\begin{array}{c}\text { Produção de conídios /g } \\
\text { de arroz }\left(\times 10^{9}\right)^{1,2}( \pm \mathrm{EP})^{*}\end{array}$ \\
\hline IBCB 351 & $1,67 \pm 0,54 \mathrm{ab}$ \\
IBCB 353 & $1,31 \pm 0,59 \mathrm{~b}$ \\
IBCB 383 & $2,25 \pm 0,58 \mathrm{ab}$ \\
IBCB 384 & $1,67 \pm 0,49 \mathrm{ab}$ \\
IBCB 410 & $1,90 \pm 0,26 \mathrm{ab}$ \\
IBCB 417 & $2,52 \pm 1,25 \mathrm{a}$ \\
IBCB 418 & $2,20 \pm 0,46 \mathrm{ab}$ \\
IBCB 425 & $2,29 \pm 0,38 \mathrm{ab}$ \\
IBCB 481 & $2,46 \pm 1,06 \mathrm{a}$ \\
\hline
\end{tabular}

*Erro padrão da média.

${ }^{1}$ Médias seguidas de mesma letra não diferem entre si pelo teste de Duncan a $5 \% .{ }^{2}$ Médias originais, transformadas para análise por $\sqrt{\mathrm{x}+0,5}$.

LOUREIRO et al. (2005b), analisando a produção em arroz pré-cozido de isolados selecionados de $M$. anisopliae visando o controle da cigarrinha-da-raiz da cana-de-açúcar, observaram que a quantidademédia de conídios variou entre 0,86 a 2,30 x $10^{10}$ conidios / $\mathrm{g}$ para o isolado IBCB 425 sendo o mais produtivo, estando esses dados 10 vezes abaixo dos valores encontrados para o isolado IBCB 417 com 2,52 x 109 conídios/g de arroz.

Produzindo em condições semelhantes, TAKADA (2002) observou o rendimento médio de três isolados de $M$. anisopliae e constatou que os valores oscilaram entre 2,25 a 2, $4 \times 10^{8}$ conídios por grama de arroz.

Os valores citados acima estão abaixo dos valores encontrados nos resultados dos testes de produção, porém, segundo TAMAI (1997), essas diferenças 
na produção de conídios entre os isolados podem estar relacionadas com a dificuldade de se reproduzir, entre um experimento e outro, todas as condições disponíveis para o crescimento do fungo em arroz, tais como: umidade e tempo de cozimento do arroz, variações na temperatura e nível de contaminação.

Assim, considerando os mais altos valores do número de conídios por grama de arroz para o fungo M. anisopliae, os isolados com melhor potencial são o IBCB 417 e 481. Para Alves (1998) a quantidade de conídios é um fator de seleção importante em um isolado, pois quanto maior sua produção maior será o potencial de inoculo, em determinada quantidade de arroz mais fungo a ser utilizada, viabilizando melhor o custo desse controle.

\section{CONCLUSÕES}

Todos os isolados testados são patogênicos à $D$. saccharalis em condições de laboratório. Os isolados mais virulentos de M. anisopliae são os IBCB 384, 383, 481,418 e417, sendo quea maior produção deconídios de $M$. anisopliae é obtida com os isolados IBCB 481 e 417.

\section{AGRADECIMENTOS}

À Fundação de Amparo a Pesquisa do Estado de SãoPaulo(FAPESP) pelo financiamento deste projeto e a Usina São João pela concessão das lagartas da broca da cana-de-açúcar.

\section{REFERÊNCIAS}

ACEVEDO, J.P.M.; SAMUELS, R.I.; MACHADO, I.R.; DOLINSKI, C. Interactions between isolates of the entomopathogenic fungus Metarhizium anisopliae and the entomopathogenic nematode Heterorhabditis bacteriophora during infection of the sugar cane borer Diatraea saccharalis. Journal of Invertebrate Pathology, v.96, p.187-192, 2007.

ALVES, S.B. Controle microbiano de insetos. Piracicaba: FEALQ, 1998. 1163p.

CÉSAR FILHO, E.; MARQUES, E.J.; BARROS, R. Selection of Metarhizium anisopliae (Metsch.) and Beauveria bassiana (Bals.) isolates to control Alabama argillacea (Huebner) caterpillars. Scientia Agrícola, v.59, n.3, p.457-462, 2001.

CINTRA, E.R.R.; ALMEIDA, J.E.M.; BATISTA FILHO, A.; SANO, A.H.; ZAPPELINI, L.O.; WENZEL, I.M.; AZEVEDO FILHO, J.A. Seleção de Isolados de
Metarhizium anisopliae para o controle da cigarra do café Fidicina sp. Arquivos do Instituto Biológico, São Paulo, v.70, 2003. Suplemento 3. Trabalho apresentado na REUNIÃO ANUAL DO INSTITUTO BIOLÓGICO, 16. 2003, São Paulo. Resumo. 1CDROM.

FAVA, F.D.; IMWINKELRIED, J.M.; TRUMPER,E.V. Manejo del barrenador del tallo de maiz Diatraea saccharalis (Lepidóptera:Crambidae) Boletin del Instituto Nacional de Tecnologia Agropecuária, n.6, p.1-4, 2004.

FIGUEIRÊDO, M.F.S.; MARQUES, E.J.; LIMA, R.O.R.; OLIVEIRA, J.V. Screening of Beauveria bassiana (Bals.) Vuill. and Metarhizium anisopliae (Metsch.) Sorok. isolates against the giant borer of sugarcane Castnia licus (Drury) (Lepidoptera: Castniidae) Neotropical Entomology, v.31, n.3, 2002.

GALLO, D; NAKANO, O.; SIVEIRA NETO, S.; CARVALHO, R.P.L.; BAPTISTA, G.C.; BERTI FILHO, E.; PARRA, J.R.P.; ZUCCHI, R.A.; ALVES, S.B.; VENDRAMIM, J.D.; MARCHINI, L.C.; LOPES, J.R.S.; OMOTO, C. Manual de entomologia agrícola. Piracicaba: FEALQ, 2002. 920p.

INSTITUTO DE ECONOMIA AGRÍCOLA (São Paulo). Previsão da safra 2007/2008 de cana-de-açúcar. 2008. Disponível em: <http:// www.iea.sp.gov.br/ estatistica>. Acesso em: 3 set. 2008.

LOUREIRO, E. de S.; BATISTA FILHO, A.; ALMEIDA, J.E.M.; PESSOA, L.G.A. Seleção de isolados de Metarhizium anisopliae (Metsch.) Sorok. contra a cigarrinha-da-raiz da cana-de-açúcar, Mahanarva fimbtiolata (Stal, 1854) (Hemíptera: Cercopidae) em laboratório. Neotropical Entomology, v.34, n.5, p.791-798, 2005a.

LOUREIRO, E. de S.; BATISTA FILHO, A.; ALMEIDA, J.E.M.; PESSOA, L.G.A. Produção de isolados de Metarhizium anisopliae, selecionados para o controle de Mahanarva fimbriolata (Stal, 1854). Arquivos do Instituto Biológico, São Paulo, v. 72, n. 4, p.469-472, 2005b.

PINTO, A. de S. Controle de pragas da cana-de-açúcar. Piracicaba, 2006. 64p. (Boletim Técnico. Biocontrol, n.1).

REIS, R.C.S.; MELO, D.R; SOUZA, E.R.; BITTENCOURT, V.R.E.P. Ação in vitro de Beauveria bassiana e Metarhizium anisopliae em Amblyoma sp. Arquivos Brasileiros de Medicina Veterinária e Zootecnia, v.53, n.5, p.544-547, 2001.

SILVA, V.C.A. Suscetibilidade de Plutella xylostella (L.) (Lepidoptera: Plutellidae) aos fungos Beauveria bassiana (Bals.) Vuill. e Metarhizium anisopliae(Metsch.) Sorok. Neotropical Entomology, v.32, n.4, p.653-658, 2003.

TAKADA, H.M. Patogenicidade e seleção de isolados de Metarhizium anisopliae (Metsch.) Sorokin e Beauveria 
bassiana (Balls.) Vuill. para o controle de Oryzophagus oruzae (Costa Lima, 1936) (Coleóptera: Curcilionidae). 2002. 75f. Dissertação (Mestrado em Agronomia) - Faculdade de Ciências Agronômicas, Universidade Estadual Paulista, Botucatu, 2002.

TAMAI, M.A. Avaliação de fungos entomopatogênico para o controle de Tetranychus urticae Koch. 1997. 86f. Dissertação (Mestrado em Agronomia) - Escola Superior de Agricultura "Luiz de Queiroz", Universidade de São Paulo, Piracicaba, 1997.

UDOP - UNIÃO DOS PRODUTORES DE BIOENERGIA. 2008. Disponível em: <http:/ /www.udop.com.br/ download/estatistica/acomp_safra_bra_0708_seg_ levantamento.pdf>. Acesso em: 3 set. 2008.
UNICA - União da Agroindústria Canavieira de São Paulo. 2008. Disponível em: <http://www.unica.com. br/estatistica>. Acesso em: 3 set. 2008.

XAVIER, L.M.S.; ÁVILA, C.J. Patogenicidade, DL50 e TL50 de isolados de Metarhizium anisopliae (Metsch.) Sorok. para o percevejo castanho das raízes Scaptocoris carvalhoi Becker (Hemiptera: Cydnidae). Ciência Rural, v.35, n.4, p.763-768, 2005.

Recebido em 24/11/08

Aceito em 18/1/09 